Article

\title{
Evaluation of the Association between Menstrual Cycle Irregularity and Dental Pain or Chewing Discomfort in Women before Menopause
}

\author{
In-Seok Song ${ }^{1}$, Eun Young $\mathrm{Ki}^{2}$, Kyungdo Han ${ }^{3}$, Jae-Jun Ryu ${ }^{4}$ and Jun-Beom Park ${ }^{5, * \mathbb{C}}$ \\ 1 Department of Oral and Maxillofacial Surgery, Korea University Anam Hospital, Seoul 02841, Korea; \\ sis80@naver.com \\ 2 Department of Obstetrics and Gynecology, College of Medicine, The Catholic University of Korea, \\ Seoul 06591, Korea; mdkey@catholic.ac.kr \\ 3 Department of Biostatistics, College of Medicine, The Catholic University of Korea, Seoul 06591, Korea; \\ hkd917@naver.com \\ 4 Department of Prosthodontics, Korea University Anam Hospital, Seoul 02841, Korea; koprosth@gmail.com \\ 5 Department of Periodontics, College of Medicine, The Catholic University of Korea, Seoul 06591, Korea \\ * Correspondence: jbassoonis@yahoo.co.kr; Tel.: +82-10-4325-2651
}

Received: 5 February 2019; Accepted: 29 March 2019; Published: 4 April 2019

\begin{abstract}
This study was performed to assess the relationship between menstrual irregularity and dental pain or chewing discomfort in women before menopause, using nationally representative data. This study analyzed 4595 participants who were $\geq 19$ years or older, and did not have missing values for outcome variables from the Korean National Health and Nutrition Examination Survey. Tooth pain was considered present if the participant felt throbbing discomfort, pain, or sensitivity when eating hot or cold food or drinking hot or cold beverages. Self-reported oral chewing discomfort was obtained. Adjusted odds ratios and their $95 \%$ confidence intervals for tooth pain in the individuals with menstrual cycle irregularity were $1.30(1.05,1.62)$ after adjustment for age, body mass index, drinking, smoking, income, exercise, stress, metabolic syndrome, and the frequency of tooth brushing. Adjusted odds ratios and their $95 \%$ confidence intervals for chewing discomfort in the individuals with menstrual cycle irregularity were $1.33(1.03,1.72)$ after adjustment. The association between menstrual irregularity and dental pain or chewing discomfort in women before menopause was proven-after adjusting for confounding factors—by multiple logistic regression analyses. Menstrual cycle irregularity may be considered a potential risk indicator for dental pain or chewing discomfort in Korean women before menopause.
\end{abstract}

Keywords: epidemiology; mastication; menstrual cycle; nutrition surveys; oral health; toothache

\section{Introduction}

Menstrual cycles can be considered important indicators of health and fertility [1,2]. Previous studies have shown the association between menstrual cycle irregularity and systemic diseases. Menstrual cycle length has been suggested as a predictor of cardiovascular disease and a breast cancer risk factor [3]. Women with long (a usual cycle length of 40 days or more) or highly irregular menstrual cycles have a significantly increased risk for developing type 2 diabetes mellitus [4], and the prevalence of type 2 diabetes is higher among women with a history of menstrual irregularity [5]. Moreover, it was reported that menstrual cycle irregularity can be considered a marker of metabolic disorders [6].

The effect of menstrual cycle on oral health has been suggested previously $[2,7,8]$. Fluctuation in estrogen/progesterone levels has been shown to affect the periodontium [7]. Sex hormones are reported to have the ability to proliferate specific periodontal microorganisms and affect host immunologic 
response [8]. Moreover, it has been shown that there is an association between menstrual cycle irregularities and periodontal treatment needs [2]. It was hypothesized that there is no significant association between menstrual irregularity and dental pain or chewing discomfort. Thus, this study was performed to assess the relationship between menstrual irregularity and dental pain or chewing discomfort in women before menopause using nationally representative data, and this is the first study to evaluate this topic.

\section{Experimental Section}

\subsection{Participants}

This study is a secondary data analysis of the Korean National Health and Nutrition Examination Survey (KNHANES) V, conducted in 2010-2012 by the Korean Ministry of Health and Welfare. The KNHANES, which is conducted annually to monitor the general health and nutritional status of the Republic of Korea population, is composed of a health interview survey, a health examination survey, and a nutritional survey by the trained staff members. A rolling sample design involving stratified, complex, and multistage probability samples was applied to gather the data. The Institutional Review Board of the Korea Centers for Disease Control approved this KNHANES and informed consent was obtained from all participants. Approval of this study was obtained by the Institutional Review Board at the Catholic University of Korea. This research was conducted based on the Helsinki Declaration-based ethical principles for medical research involving human subjects. All data analyzed during this study are included in this published article. The complete data for this study was obtained at [9].

\subsection{Anthropometric Measurement and Definition of Variables}

A total of 25,534 individuals were candidates in the KNHANES and we selected participants $\geq 19$ years. Individuals who had missing values for outcome variables were excluded from this study. Finally, 4595 subjects were included in our analysis.

Trained staff members carried out anthropometric measurements. Participants wore light clothing when measuring body weight and height. Body mass index (BMI) was defined using the following formula: $\mathrm{BMI}=$ weight $(\mathrm{kg}) /$ height $\left(\mathrm{m}^{2}\right)$. Waist circumference was measured at the approximate midpoint between the lower margin of the last palpable rib and top of the iliac crest at the end of a normal expiration.

Individuals were categorized using the criterion for alcohol consumed within one month based on the respondents' responses on the self-reported questionnaire [10]. Smoking status was categorized as current smoker or not from the interview. Individuals were regarded as exercisers if they performed moderate exercise more than 5 times per week for over $30 \mathrm{~min}$ per session, or performed vigorous exercise more than 3 times per week for over $20 \mathrm{~min}$ per session [11]. Recognition of stress was self-reported. Data regarding menstrual cycle irregularity was collected by asking the participants to recall the duration of the menstrual cycle, and menstrual cycle characteristics were categorized as regular or irregular.

Blood samples were collected from the participants' antecubital vein after fasting $>8 \mathrm{~h}$, and concentrations of serum fasting plasma glucose, total cholesterol, triglycerides, and high-density lipoprotein cholesterol were calculated. The American Heart Association/National Heart, Lung, and Blood Institute provided the Scientific Statement of the criteria for Asians for metabolic syndrome [12]. Three or more of the following criteria must be satisfied to be diagnosed with metabolic syndrome: elevated triglycerides $(150 \mathrm{mg} / \mathrm{dL}$ or greater) or use of lipid-lowering medication; high-density lipoprotein cholesterol of lower than $40 \mathrm{mg} / \mathrm{dL}$ in men or lower than $50 \mathrm{mg} / \mathrm{dL}$ in women, or use of medication; waist circumference of $90 \mathrm{~cm}$ or higher in men or $80 \mathrm{~cm}$ or higher in women; blood pressure of 130/85 $\mathrm{mm} \mathrm{Hg}$ or higher or use of antihypertensive medication; and fasting blood glucose of $100 \mathrm{mg} / \mathrm{dL}$ or higher or current use of antidiabetic medication. 


\subsection{Oral Health Behaviors and Definition of Number of Natural Teeth}

Tooth pain was considered present if the participant felt throbbing discomfort, pain, or sensitivity when eating hot or cold food or drinking hot or cold beverages. Self-reported oral chewing discomfort was obtained. The time of day when participants brushed their teeth was recorded as oral health behavior [13]. We calculated the frequency of daily tooth brushing by the total number of times the teeth were brushed each day. The number of natural teeth was calculated when primary or permanent teeth were present.

\subsection{Statistical Analysis}

The results of this study are demonstrated as means \pm standard errors for continuous variables, and as proportions (standard errors) for categorical variables. Logarithmic transformations were applied for variables having skewed distributions, when it seemed necessary. The differences in characteristics according to the presence of menstrual cycle irregularity were evaluated by a chi-square test for categorical variables or an independent $t$-test for continuous variables. A hierarchical multivariable logistic regression analysis was used to evaluate the risk of tooth pain and chewing discomfort in relation to menstrual cycle irregularity.

The risk of tooth pain and chewing discomfort was identified by evaluating the odds ratios and $95 \%$ confidence intervals. In model two, adjustments were made for age, body mass index, smoking, drinking, exercise, and income. Model three was adjusted like model 2 plus metabolic syndrome, stress, and the frequency of tooth brushing. SAS software version 9.2 was used for statistical analyses (SAS Institute, Cary, NC, USA). Statistical significance was set at $P$-value of $<0.05$.

\section{Results}

Table 1 describes the baseline characteristics of the study individuals according to the menstrual cycle irregularity. Body mass index, smoking, white blood cell count, and metabolic syndrome were significantly higher in participants with menstrual cycle irregularity. Higher education was significantly lower in participants with menstrual cycle irregularity.

Table 1. Baseline characteristics of study participants according to menstrual cycle irregularity.

\begin{tabular}{|c|c|c|c|}
\hline & \multicolumn{3}{|c|}{ Menstrual Cycle Irregularity } \\
\hline & No & Yes & $P$-Value * \\
\hline Unweighted $\mathrm{n}$ & 3940 & 655 & \\
\hline Tooth pain (yes) & $30.0(1.0)$ & $35.4(2.3)$ & 0.02 \\
\hline Chewing (discomfort) & $13.8(0.7)$ & $17.37(1.7)$ & 0.02 \\
\hline Age (years) & $35.5 \pm 0.2$ & $34.9 \pm 0.5$ & 0.27 \\
\hline Body mass index $\left(\mathrm{kg} / \mathrm{m}^{2}\right)$ & $22.4 \pm 0.1$ & $23.2 \pm 0.2$ & $<0.01$ \\
\hline Alcohol within one month & $52.3(1)$ & $48.8(2.5)$ & 0.18 \\
\hline Smoking (currently) & $5.9(0.5)$ & $8.8(1.4)$ & 0.02 \\
\hline Exercise (yes) & $16.9(0.8)$ & $17.5(1.8)$ & 0.77 \\
\hline Income (the lowest quartile) & $8.5(0.7)$ & $9.2(1.5)$ & 0.63 \\
\hline Education (high school graduate or higher) & $44.9(1.1)$ & $31.5(2.3)$ & $<0.01$ \\
\hline White blood cell $\left(\times 10^{9} / \mathrm{L}\right)^{* *}$ & $74.6 \pm 0.2$ & $76.4 \pm 0.5$ & $<0.01$ \\
\hline Stress (yes) & $32.3(0.9)$ & $39.8(2.2)$ & $<0.01$ \\
\hline Metabolic syndrome & $10.4(0.6)$ & $14.3(1.6)$ & 0.01 \\
\hline Number of natural teeth & $27.1 \pm 0.03$ & $26.92 \pm 0.11$ & 0.13 \\
\hline Frequency of tooth brushing per day & & & $<0.01$ \\
\hline$\leq 1$ & $3.8(0.4)$ & $5.8(1.0)$ & \\
\hline 2 & $37.6(1.0)$ & $42.7(2.3)$ & \\
\hline$\geq 3$ & $58.5(1.0)$ & $51.6(2.5)$ & \\
\hline Speech (discomfort) & $2.7(0.3)$ & $5.5(1.1)$ & $<0.01$ \\
\hline Dental checkup within 1 year (yes) & $12.7(0.7)$ & $9.4(1.3)$ & 0.04 \\
\hline
\end{tabular}

Data are presented as means \pm standard error or percentages (standard error). * $P$-values were obtained by independent $t$-test for continuous variables or chi-square test for categorical variables. ${ }^{* *}$ Log transformation was applied to the value, and geometric mean (95\% confidence interval) is shown. 
Figure 1 shows the percentage of menstrual cycle irregularity regarding the presence of tooth pain or chewing discomfort ( $P$ for trend: 0.0112). Figure 2 shows the percentage of tooth pain regarding the menstrual cycle; the $P$-value for the trend was 0.0661 . The percentage of individuals with tooth pain was $30.0 \pm 1.0 \%$ for regular menstrual cycles. The percentages of individuals with tooth pain with irregular menstrual cycles of once in three months and duration longer than three months were $35.1 \pm 2.5 \%$ and $36.7 \pm 5.5 \%$, respectively. Figure 3 shows the percentage of chewing discomfort regarding the menstrual cycle $(P$-value for trend $<0.01)$. The percentages of individuals with chewing discomfort were $13.8 \pm 0.7 \%, 16.1 \pm 1.8 \%$, and $25.4 \pm 4.4 \%$ for individuals with regular menstrual cycles, irregular menstrual cycles of once in three months, and duration longer than three months, respectively.

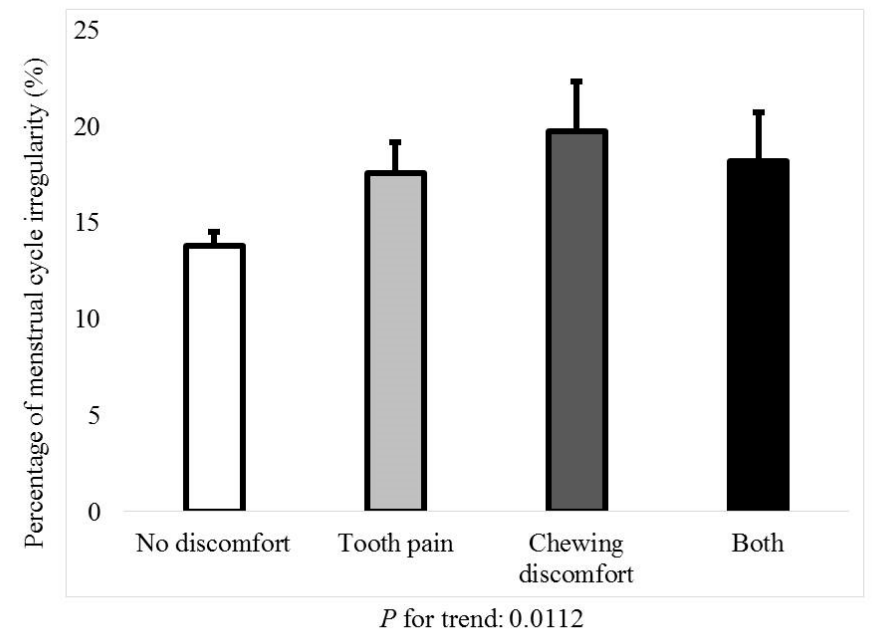

Figure 1. Percentage of menstrual cycle irregularity in the individuals with tooth pain and/or chewing discomfort.

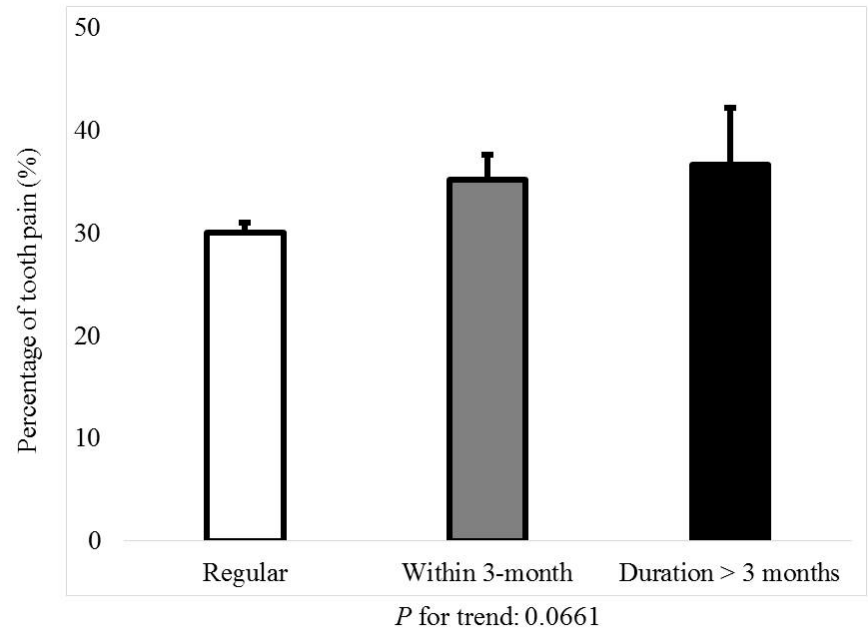

Figure 2. Percentage of tooth pain according to menstrual cycle categorization of regular, irregular (once within 3 months), and duration longer than 3 months. 


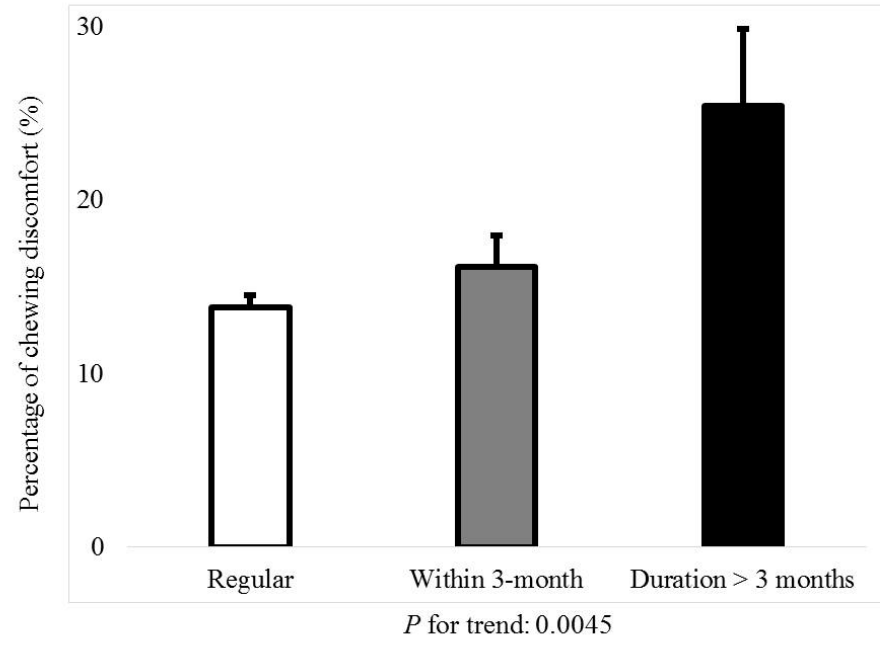

Figure 3. Percentage of chewing discomfort by menstrual cycle irregularity.

Table 2 shows the effects of oral health on the menstrual cycle irregularity. The percentage of tooth pain, chewing discomfort, and speech discomfort was statistically higher with menstrual cycle irregularity $(P<0.05)$. Table 3 shows the adjusted odds ratios and their $95 \%$ confidence intervals from multivariate logistic regression analyses for individuals with tooth pain and chewing discomfort. Adjusted odds ratios and their $95 \%$ confidence intervals for tooth pain in individuals with menstrual cycle irregularity were $1.30(1.05,1.62)$ after adjustment for age, body mass index, smoking, drinking, exercise, income, metabolic syndrome, stress, and frequency of tooth brushing. Adjusted odds ratios and their $95 \%$ confidence intervals for chewing discomfort in individuals with menstrual cycle irregularity were $1.33(1.03,1.72)$ after adjustment.

Table 2. The effects of oral health on menstrual cycle irregularity.

\begin{tabular}{cccc}
\hline & \multicolumn{3}{c}{ Menstrual Cycle Irregularity } \\
\hline & No & Yes & P-Value \\
\hline $\mathrm{n}$ & 3940 & 655 & \\
Tooth pain (yes) & $30.0(1.0)$ & $35.4(2.3)$ & 0.02 \\
Chewing (discomfort) & $13.8(0.7)$ & $17.7(1.7)$ & 0.02 \\
$\leq 1$ & & & 0.01 \\
2 & $3.8(0.4)$ & $5.8(1.0)$ & \\
$\geq 3$ & $37.6(1)$ & $42.7(2.3)$ & \\
Frequency of tooth brushing per day & $58.5(1)$ & $51.6(2.5)$ & \\
Speech (discomfort) & $2.7(0.3)$ & $5.5(1.1)$ & $<0.01$ \\
Dental checkup within 1 year (yes) & $12.7(0.7)$ & $9.4(1.3)$ & 0.04 \\
\hline
\end{tabular}

Data are presented as percentages (SE).

Table 3. Adjusted odds ratios and $95 \%$ confidence intervals of the individuals with tooth pain or chewing discomfort in multivariate logistic regression models in the presence of menstrual cycle irregularity.

\begin{tabular}{ccccc}
\hline & Tooth Pain & \multicolumn{3}{c}{ Chewing Discomfort } \\
\hline & Odds Ratio (95\% Confidence Interval) & $\boldsymbol{P}$-Value & Odds Ratio (95\% Confidence Interval) & $\boldsymbol{P}$-Value \\
\hline Model 1 & $1.23(1.05,1.60)$ & 0.02 & $1.35(1.05,1.74)$ & 0.02 \\
Model 2 & $1.28(1.04,1.58)$ & 0.02 & $1.37(1.06,1.77)$ & 0.02 \\
Model 3 & $1.30(1.05,1.62)$ & 0.02 & $1.33(1.03,1.72)$ & 0.03 \\
\hline
\end{tabular}

Model 1: No adjustment. Model 2: Model $1+$ age, body mass index, smoking, drinking, exercise, and income adjusted. Model 3: Model $2+$ metabolic syndrome, stress, and the frequency of tooth brushing adjusted. 


\section{Discussion}

This association may be explained by the following. Risk factors in the menstrual cycle were evaluated, and it was suggested that psychological stress and obesity may be related to menstrual cycle characteristics [14]. The results of this study showed that stress was significantly higher in participants with menstrual cycle irregularity. It was noted that cycle irregularity was associated with psychosocial stress [15]. High stress levels—greater than 20 using the Perceived Stress Scale-were associated with menstrual cycle irregularity [16]. High levels of psychological distress were significantly associated with poor self-rated oral health after adjustment for confounding factors [17]. Moreover, stress may alter the hypothalamic-pituitary-ovarian axis $[18,19]$, and a shift in the axis may produce changes in pain sensitivity. One report showed that the menstrual cycle was associated with pain experience, and the increase in pain perception among females during their perimenstrual period was significantly greater than their postmenstrual period [20].

This study indicated that body mass index was higher for participants with menstrual cycle irregularity. Similarly, a previous report showed that menstrual cycle irregularity was associated with overall obesity [21]. Obese individuals had higher odds of having tooth loss [22]. The mean decayed, missing, and filled teeth index value was higher in obese participants when compared with nonobese individuals [23], and a significant positive correlation between body mass index and dental caries was suggested after controlling for potential confounders [24]. Similarly, body mass index has been shown to exert an influence on masticatory performance [25]. In obese women, especially with central obesity, the absorbed steroid is transformed into estrogen in peripheral fat [26,27], and the change in the level of estrogen may produce tooth pain [28]. However, another study reported that body mass index was related to periodontitis but not to dental caries [29]. In another report, dental caries had no significant relationship with abdominal obesity [30]. Menstrual cycle irregularity was suggested to be a potential risk indicator for periodontal disease [2], which may explain the association between menstrual cycle irregularity and chewing discomfort.

Disordered eating is strongly related to menstrual irregularity [31]. Menstrual regularity can be influenced by specific dietary nutrients that may have direct effects or exert their effects by modulating circulating sex steroid status [32]. The incidence of menstrual irregularity was $4.9 \%$ among non-vegetarians and $26.5 \%$ among vegetarians [32]. Thus, diet may explain the relationship between menstrual cycle irregularity and dental pain.

Various methods have been used to assess menstrual cycle characteristics [2,33,34]. Our previous report categorized the menstrual cycle as regular, irregular (once within three months), or duration longer than three months [2]. In another report, the periods were defined as regular if the overall range was within 20 to 40 days [33]. In other research, menstrual cycle difference was calculated as the difference (in days) between the longest and shortest menstrual cycle in the past 12 months, and the menstrual cycle was considered irregular if the difference was $\geq 15$ days [33,34]. These various methods for evaluating menstrual irregularity in each research may produce different results.

This study had several limitations. Firstly, the measurement of menstrual regularity is at best an approximation of female reproductive status, because regular cycles may, in fact, be anovulatory or mask luteal-phase inadequacies that can be detected only by direct hormone-concentration measurements [32]. Secondly, the exact length of the cycle was not reported, and issues may arise from the use of recalled menstrual histories [32]. A previous study reported that there were considerable measurement errors in self-reported cycle length and the recollection of menstrual cycle length $[35,36]$. However, the collection of information regarding menstrual cycle by survey is a widely used method [37]. KNHANES applied a rolling sampling design while obtaining the data used in this study, which involves complex, stratified, and multistage probability samples-and these methods allows the data to be considered as a nationally representative result. The association between menstrual irregularity and dental pain or chewing discomfort in women before menopause was discovered by multiple logistic regression analyses after adjusting for confounding factors, and consequently, the results can be considered representative and reliable. 


\section{Conclusions}

The association between menstrual irregularity and dental pain or chewing discomfort in women before menopause was proven—after adjusting for confounding factors—by multiple logistic regression analyses. Menstrual cycle irregularity may be considered a potential risk indicator for dental pain or chewing discomfort in Korean women before menopause.

Author Contributions: Conceptualization, I.-S.S., E.Y.K., K.H., J.-J.R. and J.-B.P.; methodology, I.-S.S., E.Y.K., K.H., J.-J.R. and J.-B.P.; validation, I.-S.S., E.Y.K., K.H., J.-J.R. and J.-B.P.; formal analysis, I.-S.S., E.Y.K., K.H., J.-J.R. and J.-B.P.; writing — original draft preparation, I.-S.S., E.Y.K., K.H., J.-J.R. and J.-B.P.; and writing-review and editing, I.-S.S., E.Y.K., K.H., J.-J.R. and J.-B.P.

Funding: This research received no external funding.

Acknowledgments: The authors thank the Korea Centers for Disease Control and Prevention for providing the data.

Conflicts of Interest: The authors declare no conflicts of interest.

\section{References}

1. Van Anders, S.M.; Watson, N.V. Menstrual cycle irregularities are associated with testosterone levels in healthy premenopausal women. Am. J. Hum. Biol. 2006, 18, 841-844. [CrossRef] [PubMed]

2. Han, K.; Ko, Y.; Park, Y.G.; Park, J.B. Associations Between the Periodontal Disease in Women Before Menopause and Menstrual Cycle Irregularity: The 2010-2012 Korea National Health and Nutrition Examination Survey. Medicine 2016, 95, e2791. [CrossRef] [PubMed]

3. Jukic, A.M.; Weinberg, C.R.; Wilcox, A.J.; McConnaughey, D.R.; Hornsby, P.; Baird, D.D. Accuracy of reporting of menstrual cycle length. Am. J. Epidemiol. 2008, 167, 25-33. [CrossRef] [PubMed]

4. Solomon, C.G.; Hu, F.B.; Dunaif, A.; Rich-Edwards, J.; Willett, W.C.; Hunter, D.J.; Colditz, G.A.; Speizer, F.E.; Manson, J.E. Long or highly irregular menstrual cycles as a marker for risk of type 2 diabetes mellitus. JAMA 2001, 286, 2421-2426. [CrossRef] [PubMed]

5. Roumain, J.; Charles, M.A.; de Courten, M.P.; Hanson, R.L.; Brodie, T.D.; Pettitt, D.J.; Knowler, W.C. The relationship of menstrual irregularity to type 2 diabetes in Pima Indian women. Diabetes Care 1998, 21, 346-349. [CrossRef]

6. Rostami Dovom, M.; Ramezani Tehrani, F.; Djalalinia, S.; Cheraghi, L.; Behboudi Gandavani, S.; Azizi, F. Menstrual Cycle Irregularity and Metabolic Disorders: A Population-Based Prospective Study. PLoS ONE 2016, 11, e0168402. [CrossRef]

7. Machtei, E.E.; Mahler, D.; Sanduri, H.; Peled, M. The effect of menstrual cycle on periodontal health. J. Periodontol. 2004, 75, 408-412. [CrossRef]

8. Koreeda, N.; Iwano, Y.; Kishida, M.; Otsuka, A.; Kawamoto, A.; Sugano, N.; Ito, K. Periodic exacerbation of gingival inflammation during the menstrual cycle. J. Oral Sci. 2005, 47, 159-164. [CrossRef] [PubMed]

9. Korea Centers for Disease Control \& Prevention. Available online: https://knhanes.cdc.go.kr (accessed on 25 March 2016).

10. Agarwal, D.P. Cardioprotective effects of light-moderate consumption of alcohol: A review of putative mechanisms. Alcohol Alcohol. 2002, 37, 409-415. [CrossRef] [PubMed]

11. Oh, J.Y.; Yang, Y.J.; Kim, B.S.; Kang, J.H. Validity and reliability of Korean version of International Physical Activity Questionnaire (IPAQ) short form. J. Korean Acad. Fam. Med. 2007, 28, 532-541.

12. Chun, Y.H.; Kim, H.R.; Han, K.; Park, Y.G.; Song, H.J.; Na, K.S. Total cholesterol and lipoprotein composition are associated with dry eye disease in Korean women. Lipids Health Dis. 2013, 12, 84. [CrossRef]

13. Kim, Y.H.; Kim, D.H.; Lim, K.S.; Ko, B.J.; Han, B.D.; Nam, G.E.; Park, Y.G.; Han, K.D.; Kim, J.H.; Cho, K.H. Oral health behaviors and metabolic syndrome: The 2008-2010 Korean National Health and Nutrition Examination Survey. Clin. Oral Investig. 2013. [CrossRef]

14. Chang, P.J.; Chen, P.C.; Hsieh, C.J.; Chiu, L.T. Risk factors on the menstrual cycle of healthy Taiwanese college nursing students. Aust. N. Z. J. Obstet. Gynaecol. 2009, 49, 689-694. [CrossRef]

15. Kollipaka, R.; Arounassalame, B.; Lakshminarayanan, S. Does psychosocial stress influence menstrual abnormalities in medical students? J. Obstet. Gynaecol. 2013, 33, 489-493. [CrossRef] 
16. Nagma, S.; Kapoor, G.; Bharti, R.; Batra, A.; Batra, A.; Aggarwal, A.; Sablok, A. To evaluate the effect of perceived stress on menstrual function. J. Clin. Diagn. Res. 2015, 9, Qc01. [CrossRef] [PubMed]

17. Amarasena, N.; Kapellas, K. Psychological distress and self-rated oral health among a convenience sample of Indigenous Australians. J. Public Health Dent. 2015, 75, 126-133. [CrossRef] [PubMed]

18. Young, E.A.; Midgley, A.R.; Carlson, N.E.; Brown, M.B. Alteration in the hypothalamic-pituitary-ovarian axis in depressed women. Arch. Gen. Psychiatry 2000, 57, 1157-1162. [CrossRef] [PubMed]

19. Kyrou, I.; Tsigos, C. Chronic stress, visceral obesity and gonadal dysfunction. Horm. (Athens) 2008, 7, $287-293$. [CrossRef]

20. Ozcaka, O.; Bicakci, N.; Kose, T. Effect of the menstrual cycle on pain experience associated with periodontal therapy: Randomized, pilot study. J. Clin. Periodontol. 2005, 32, 1170-1174. [CrossRef]

21. Mustaqeem, M.; Sadullah, S.; Waqar, W.; Farooq, M.Z.; Khan, A.; Fraz, T.R. Obesity with irregular menstrual cycle in young girls. Mymensingh Med. J. 2015, 24, 161-167.

22. Nascimento, G.G.; Leite, F.R. Is there a relationship between obesity and tooth loss and edentulism? A systematic review and meta-analysis. Obes. Rev. 2016. [CrossRef]

23. Ferraz, E.G.; Silva, L.R.; Sarmento, V.A.; de Jesus Campos, E.; de Oliveira, T.F.; Magalhaes, J.C.; Paraguassu, G.M.; Boa-Sorte, N. Comparison of two visual methods for detecting caries among obese and non-obese children. Acta Odontol. Scand. 2016, 405-410. [CrossRef]

24. Alswat, K.; Mohamed, W.S.; Wahab, M.A.; Aboelil, A.A. The Association Between Body Mass Index and Dental Caries: Cross-Sectional Study. J. Clin. Med. Res. 2016, 8, 147-152. [CrossRef]

25. Consolacao Soares, M.E.; Ramos-Jorge, M.L.; de Alencar, B.M.; Marques, L.S.; Pereira, L.J.; Ramos-Jorge, J. Factors associated with masticatory performance among preschool children. Clin. Oral Investig. 2016. [CrossRef]

26. Labrie, F. DHEA, important source of sex steroids in men and even more in women. Prog. Brain Res. 2010, 182, 97-148.

27. Labrie, F.; Belanger, A.; Luu-The, V.; Labrie, C.; Simard, J.; Cusan, L.; Gomez, J.L.; Candas, B. DHEA and the intracrine formation of androgens and estrogens in peripheral target tissues: Its role during aging. Steroids 1998, 63, 322-328. [CrossRef]

28. Glueck, C.J.; McMahon, R.E.; Bouquot, J.E.; Triplett, D. Exogenous estrogen may exacerbate thrombophilia, impair bone healing and contribute to development of chronic facial pain. Cranio 1998, 16, 143-153. [CrossRef]

29. Kim, Y.S.; Kim, J.H. Body mass index and oral health status in Korean adults: The Fifth Korea National Health and Nutrition Examination Survey. Int. J. Dent. Hyg. 2016. [CrossRef]

30. Cao, X.; Wang, D.; Zhou, J.; Yuan, H.; Chen, Z. The relationship between dental caries and metabolic syndrome among 13,998 middle-aged urban Chinese. J. Diabetes 2016. [CrossRef]

31. Cobb, K.L.; Bachrach, L.K.; Greendale, G.; Marcus, R.; Neer, R.M.; Nieves, J.; Sowers, M.F.; Brown, B.W., Jr.; Gopalakrishnan, G.; Luetters, C.; et al. Disordered eating, menstrual irregularity, and bone mineral density in female runners. Med. Sci. Sports Exerc. 2003, 35, 711-719. [CrossRef]

32. Pedersen, A.B.; Bartholomew, M.J.; Dolence, L.A.; Aljadir, L.P.; Netteburg, K.L.; Lloyd, T. Menstrual differences due to vegetarian and nonvegetarian diets. Am. J. Clin. Nutr. 1991, 53, 879-885. [CrossRef]

33. Jarvelaid, M. The effect of gynecologic age, body mass index and psychosocial environment on menstrual regularity among teenaged females. Acta Obstet. Gynecol. Scand. 2005, 84, 645-649. [CrossRef]

34. Wei, S.; Schmidt, M.D.; Dwyer, T.; Norman, R.J.; Venn, A.J. Obesity and menstrual irregularity: Associations with SHBG, testosterone, and insulin. Obesity 2009, 17, 1070-1076. [CrossRef]

35. Bean, J.A.; Leeper, J.D.; Wallace, R.B.; Sherman, B.M.; Jagger, H. Variations in the reporting of menstrual histories. Am. J. Epidemiol. 1979, 109, 181-185. [CrossRef]

36. Small, C.M.; Manatunga, A.K.; Marcus, M. Validity of self-reported menstrual cycle length. Ann. Epidemiol. 2007, 17, 163-170. [CrossRef]

37. Han, K.; Ko, Y.; Park, Y.G.; Park, J.B. Associations between the number of natural teeth in postmenopausal women and duration of lactation: The 2010-2012 Korea National Health and Nutrition Examination Survey. Maturitas 2016, 85, 73-78. [CrossRef]

(C) 2019 by the authors. Licensee MDPI, Basel, Switzerland. This article is an open access article distributed under the terms and conditions of the Creative Commons Attribution (CC BY) license (http://creativecommons.org/licenses/by/4.0/). 